choriocarcinoma. Such patients often have a history of menstrual dysfunction and may have had many positive tests. Some patients, as in the second case, will have both positive and negative test results. The most likely explanation for this is that the negative test result came from a less sensitive kit. Patients with choriocarcinoma may have relatively low human chorionic gonadotrophin concentrations for months or years before the disease enters a rapid growth phase, and during this time tests with a sensitivity of $500 \mathrm{IU} / 1$ may be negative. Thus follow up tests should always be carried out with a kit of the same sensitivity as the original test.

With modern combination chemotherapy choriocarcinoma has a high cure rate even when there are metastases. ${ }^{3}$ But when the diagnosis is delayed patients may die unnecessarily or suffer avoidable morbidity as in our two cases. The correct interpretation of "false positive" pregnancy tests might go some way to eliminating such unfortunate occurrences.

We recommend that all patients who have a pregnancy test that appears to be falsely positive should have their serum human chorionic gonadotrophin concentration measured. Under such circumstances a raised concentration would strongly suggest the presence of trophoblastic tumour.

1 Anonymous. A year for new arrivals. Chemist and Druggist 1987;2:10-15.

2 Bagshawe KD, Begent RHJ. Trophoblastic tumours: clinical features and management. In: Coppleson M, ed. Gynaecologic oncology. Vol 2. Edinburgh Churchill Livingstone, 1981:757-72.

3 Newlands ES, Bagshawe KD, Begent RHJ, Rustin GJSR, Holden L, Dent J. Developments in chemotherapy for medium- and high-risk patients with gestational trophoblastic tumours (1979-84). Br $\mathcal{F}$ Obstet Gynaecol 1986; 93:63-9.

4 Edmonds DK, Lindsay KS, Miller JF, Williamson E, Wood PJ. Early embryonic mortality in women. Fertility and Sterility 1982;38:447-53.

(Accepted 16 August 1988)

\title{
Maudsley of the Maudsley
}

\section{Tony Delamothe}

"A lot of people coming at the nineteenth century from different angles have found themselves bumping into Henry Maudsley and wanting to know more about him," said Dr G E Berrios on why he had organised a symposium devoted to Henry Maudsley (1835-1918). Most of those who had bumped into him were at Robinson College, Cambridge, to share their experiences.

Not everyone from the "first rank of nineteenth century intellectual glitterati" has a symposium commemorating the 70th anniversary of their death. What brought the participants together was a sense of urgency: Maudsley, already insubstantial by the time of his death, is in danger of vanishing completely.

Quoted approvingly by Charles Darwin and read by Tolstoy, Maudsley's books are now being disposed of by librarians on the grounds that they are out of date. According to Maudsley's bibliographer, Professor Michael Collie, the New York Academy of Medicine has apparently lost its Maudsley collection, and the complete library of the West London Hospital, where Maudsley worked for many years, has disappeared without trace. ${ }^{\prime}$

When it comes to more personal details there has been less to lose. In his last book Religion and Realities (1918) Maudsley wrote that it was a ludicrous display of vanity by men of great eminence to leave behind them carefully preserved letters and elaborate memoirs of what they thought and felt. At least he had the consistency to leave almost none himself-not by giving instructions that his papers be destroyed (which only draws attention to them) but by destroying them himself. All that was left was a 4000 word biography marked private, written sometime in his $70 \mathrm{~s}$, which dealt mostly with his childhood and schooling.

Two of the Maudsley Lectures, given in his honour, have been biographical. Sir Aubrey Lewis's of 1951 was published (and is most historians' starting point); Sir Hubert Bond's of twenty years earlier, entitled "Maudsley: Testimonied in his own bringing forth" has been lost.

This makes it difficult for biographers in an age when personality is meant to unlock the secrets of a person's work. Fulsome obituaries rarely provide insights into people's lives, but in Maudsley's case, apart from his biographical fragment, obituaries are almost all there is. For what it's worth "cynical," "pessimistic," and "materialist" appear in nearly all of Maudsley's. "A great man, but not a good man. A right bastard," thought Dr Henry Rollin, present day chairman of the Royal College of Psychiatrists Group for the History of Psychiatry, freed from the obituarists' pieties. If only he had had children, the obituarists thought, perhaps his sympathies might have been wider.

Leaving so little for posterity may be counter productive: those who come later have an irresistible urge to fill the gap. Miss Patricia Allderidge, archivist and curator of the Bethlem Royal Hospital, attributed much of Maudsley's behaviour to his Yorkshire roots - "not just a Yorkshireman, but an extreme form of Yorkshireman"-making him seem like the Geoffrey Boycott of Victorian psychiatry.

At the other end of his life when Maudsley was virtually a recluse Dr Rollin detected depression, perhaps brought on by his wife's dementia (she died of "senile decay" in 1911). Maudsley's mother had died before he was 10, after which his father had hardly spoken. Was some pattern being repeated here?

The big unexplained "problem" of Maudsley's professional life was his resignation of the editorship of the Fournal of Mental Science in 1878. Was it because his critics could complain of "certain doctrines taught there, certain tenets, which are contrary and repugnant," or of his failure to advance the interests of asylum doctors? Why had Maudsley leant over backwards to insult in print his brother in law, asylum doctor Harrington Tuke, whom he had already finessed out of rewards Tuke thought were coming his way? Dr Charlotte Mackenzie, lecturer in history at Rolle College, Exmouth, gave a persuasive account of the likely basis for professional and personal rivalries between the men and why it might have come to a head in the 1870s. But then there was Crichton Browne's reminiscence that along with other psychiatrists Maudsley and Tuke would meet in Soho restaurants "to adumbrate projects for the future of lunacy,"-hardly suggesting they were implacable enemies. ${ }^{2}$

What genuinely separated Maudsley from his colleagues was his opposition to traditional religious beliefs. Being a dissenter from Yorkshire helped, but his time at University College Hospital spent reading Spencer and Comte in preference to dissection and

\section{London WC1H 9JR}

Tony Delamothe, $\mathrm{MD}$, assistant editor 


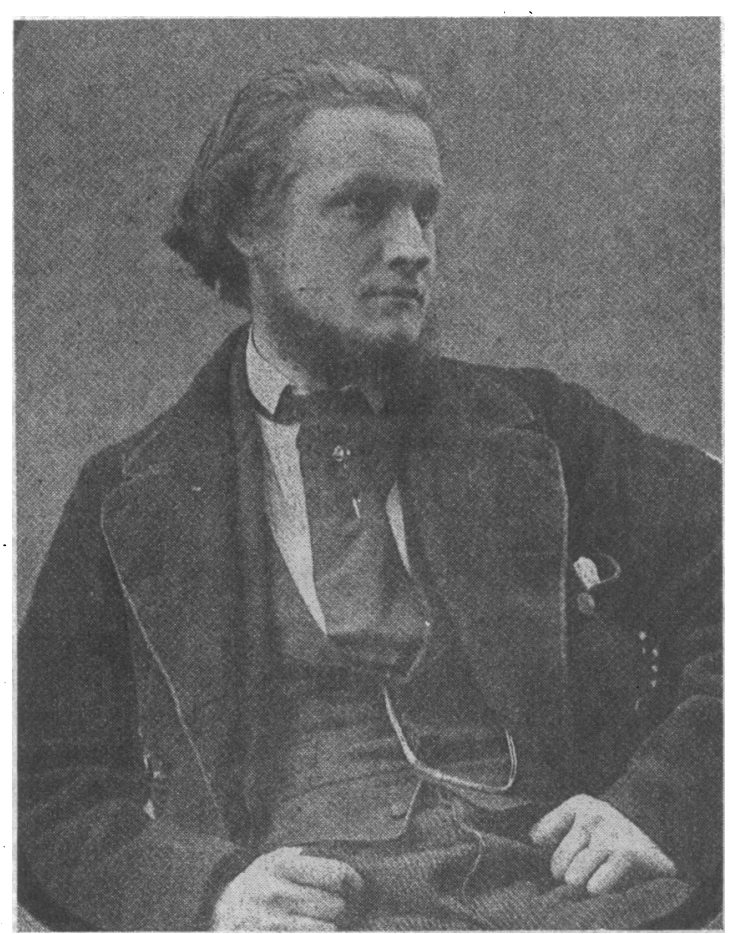

Maudsley in his 20s

midwifery probably gave him an extra push. (At that time University College was notorious for its religious freedom: it had been set up to allow non-Anglicans the education denied them by Oxford or Cambridge.) Despite his reliance on theory instead of practice Maudsley did well in his final examinations, winning 10 gold medals.

After University College Hospital he thought of joining the East India Company, for which six months' working in an asylum was a precondition of employment. He worked at West Riding Asylum in Wakefield, and presumably during this time ditched the idea of India in favour of British psychiatry.

After working at the Essex County Asylum and the Manchester Royal Lunatic Asylum he wrote that he "threw" himself on London "without any definite notion of what I should do there." To judge by his addresses he soon decided to court the large carriage trade that existed in psychiatry in London then. He also became the joint editor of the fournal of Mental Science (1863), physician at the West London Hospital (1864), lecturer on insanity at St Mary's Hospital (1868), and professor of medical jurisprudence at University College, London. ${ }^{2}$

His best career move seems to have been publishing articles soon after his arrival in London on Hamlet and middle class hospitals - two of the favourite topics of Dr John Conolly, doyen of mid-century psychiatry. Harrington Tuke had already married his elder daughter, and a month before Conolly's death Maudsley married a younger one. The lease of Lawn House (a combined residence and private asylum for six ladies) passed to Maudsley through her. "If Maudsley's marriage did not make him wealthy, it none the less increased his income and security in a timely way," writes Professor Collie, "providing the stability necessary for the completion of The Physiology and Pathology of Mind"-the first of Maudsley's 12 books.

It was the books that brought Maudsley fame, and the private practice this brought presumably allowed him to resign from the appointments he had so assiduously sought on his arrival in London. (For an unsuccessful application to become resident physician at Bethlem he had organised references from Conolly, Lawrence (surgeon to the Queen), Jenner (physician to

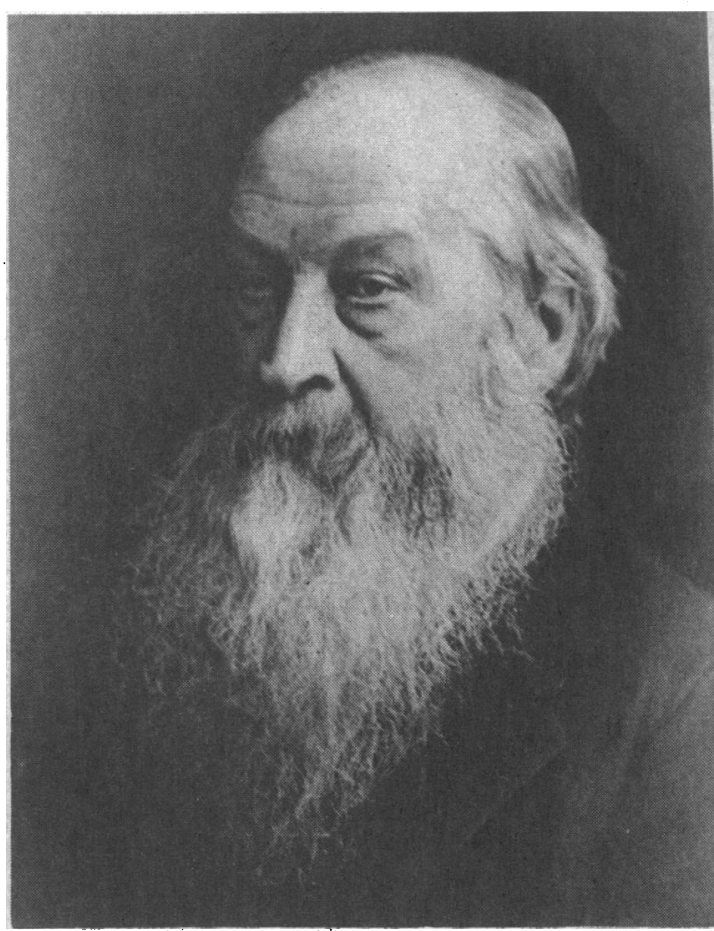

Maudsley aged 82

the Queen), Griesinger (a famous German psychiatrist), and another three British psychiatrists. ${ }^{2}$

It is assumed that he continued in private practice, although almost nothing exists to substantiate this view other than some notes he made about a "Lady D," a psychiatric patient he visited at the private Ticehurst House, and his estate, valued on his death at $£ 100000$ (worth about £lm today).

\section{The Maudsley}

Whatever else we may say about him, the Hospital must be to his credit. All his writings point to it, and it would be a miserable business to take away from the magnitude of the life's work by any revisionist ploy whatsoever.'

... the act for which he is most famed, the donation of $£ 30000$ to found the Maudsley Hospital, has ... not been analysed in detail, not least because the facts are fixed in legend. He was certainly dogged in his pursuit of the LCC [London County Council]... but it is also clear that Mott originated the idea via a preface to the Archives of Neurology (1907) after visiting Kraepelin's clinic in Munich, after which Maudsley made his financial offer, in a letter to the LCC. (At least, this is Mott's account (1921) as told in his Maudsley Lecture.) ${ }^{2}$

The idea of smalt asylums for patients with acute psychiatric illnesses had been mooted long before 1907-the large "bins" that had proliferated after the 1845 Asylum Act had long since been judged as failures for anything more than custody. But organisations responsible for psychiatric care, such as the London County Council, would hardly have been likely to initiate such a plan. Much manoeuvring behind the scenes by Maudsley and Mott (director of the Pathological Laboratory at Claybury) finally convinced them. In his biographical note Maudsley wrote, "At the last, tired of the delays, I threatened to withdraw the offer in a public letter. As an election was close at hand, and the Moderates feared that such a letter, if it appeared, might injure their chances, they soon procured a site at Denmark Hill where the Maudsley Hospital now stands."

The hospital was to take early and acute cases onlythose with a chance of recovery. Clinical, and especially pathological, research was to be done (with the Maudsley absorbing Claybury's pathological laboratory) and teaching given. Finally opened in 1923, the hospital may be the one project that lived up to 
Maudsley's expectations: according to Miss Allderidge, every chair of psychiatry in this country, with one exception, is currently filled by a psychiatrist trained at the Maudsley.

\section{The work}

With the exception of his writings in forensic psychiatry ("still relevant, the questions don't change"), the bulk of Maudsley's work went unexamined at the symposium. Trying to read his work today, you can understand why attempts at constructing a biography and reassembling his social and professional milieu are more interesting.

The main problem is that Maudsley's faith in the theory of degeneration-he was British psychiatry's greatest exponent-condemns his work to a perpetual psychiatric limbo. Degeneration depended on the inheritance of acquired characteristics, owing its main intellectual debt to Lamarck.

It was thought of as a hereditary condition, brought about initially by the adverse effects of civilisation. Once established, degeneration was transmitted from generation to generation, in a progressively more severe form. The first generation might be merely nervous and unstable, the next definitely neurotic, the third seriously mentally disturbed, and the fourth idiotic and, through sterility of its members, die out. Heredity had been frequently invoked to explain physical and mental abnormalities ("constitutions" and "diatheses" were inherited): the sting in degeneration's tale was its cumulative and progressive nature. (Writers such as Zola seized on the narrative possibilities this offered.) ${ }^{3}$

Although the unnatural excitements of civilisation got most of the blame for setting the unsuspecting (and his children's children's children) down the slippery slope, alcoholism, masturbation, and syphilis could do it too, which explains the intensity of the campaigns mounted against these three in the late nineteenth century.

Pathological changes produced by degeneration were not restricted to the psychological realm but were thought to be grounded in matter, with much anxiety about damaged "germ plasm." This explains Maudsley's insistence that pathological studies should be included at the hospital he was endowing. Sooner or later, he thought, abnormalities would be found in the nervous tissue of the psychiatrically disturbed. (If alive today Maudsley would be championing the search for a schizophrenia gene and a biochemical explanation of psychiatric illness.)

Such a view has consequences for psychiatric practice-if psychiatric illness is the result of moral degeneration then it must be incurable: moral treatments could not affect a biophysical process. For Maudsley therapeutic nihilism was the logical outcome. He was, however, against locking such people up and subjecting them to "restraint," believing that patients did just as well at home or in institutions (very like his own) that resembled home.

Degeneration played an important part in medical theories only until the end of the century, although Maudsley stuck with it, perhaps in a slightly modified form, until his death. His wish that patients with early, acute disease be investigated at the Maudsley suggests that he may have believed that some diseases had an element of reversibility. His interest at the time in "puerperal insanity," reversible in some cases, may have been evidence of a shift in attitude.

By the time he decided to endow the Maudsley his influence on contemporary psychiatry was waning. His writings, always "philosophical," became ever more esoteric and abstruse. He finished practising in 1903, when he visited Australia to see "how cricket was played." He attended Lord's regularly, and "was bowled at by professionals." Cricket analogies crop up in his later writings. He used the experienced batsman to exemplify his theory of learning, although using his model it is difficult to explain how an experienced batsman would ever get out. ${ }^{4}$ The bowler is almost absent from his account, the rest of the teams certainly are. On or off the field, Professor Collie argued, Maudsley's individuals were trapped within themselves. He never could visualise communities or societies.

"If it hadn't have been for the Maudsley Hospital would we be here today?" "I think we would," replied Dr Rollin to his own question, having warmed to the subject of the symposium over the course of the day. For cultural historians, argued Dr Pick of Cambridge's faculty of history, Maudsley is one of the exemplary late nineteenth century figures who incorporated contemporary evolutionary theories into their own theories of health and disease. (Hughlings Jackson is another.) For the rest of us, the symposium has meant that the next time we bump into Henry Maudsley we will have something to say.

Photographs courtesy of Professor Collie and the Royal College of Psychiatrists.

1 Collie M. Henry Maudsley: Victorian psychiatrist. Winchester: St Paul's Bibliographies, 1988.

Turner T. Henry Maudsley-psychiatrist, philosopher and entrepreneur. Psychol Med 1988;18:551-74.

3 Bynum WF. Alcoholism and degeneration in 19th century European medicine and psychiatry. $\mathrm{Br} \mathcal{F}$ Addict 1984;79:59-70.

4 Maudsley H. Mental organisation: an introductory chapter. fournal of Mental Science 1913;59:1-14.

Update box for Oxford Handbook of Clinical Specialties, p 99

\section{Chickenpox in pregnancy}

Varicella (chickenpox) may have serious complications in pregnancy. In a study of 43 women with varicella in pregnancy nine had associated morbidity - four had pneumonia, of whom one died and one required ventilation, and four had a premature labour, of whom two delivered prematurely.' Infection within the first 20 weeks of gestation may result in the congenital varicella syndrome (microcephaly, convulsions, and mental retardation resulting from cerebral cortical atrophy and cerebellar hypoplasia; limb hypoplasia; rudimentary digits; and pigmented $\mathrm{scars}^{2}$ ), with about $10 \%$ of the babies born to mothers infected in the first trimester being affected. When maternal infection occurs within two weeks of birth the baby may be infected at delivery and develop chickenpox after birth.

Infection may be prevented by vaccination of susceptible women before pregnancy with live varicella vaccine (when available). Antivaricella zoster immunoglobulin can prevent infection in $50 \%$ of cases when given to susceptible contacts (trials mainly in non-pregnant subjects). ${ }^{3}$ Give $1000 \mathrm{mg}$ antivaricella zoster immunoglobulin intramuscularly ${ }^{3}$ to the pregnant woman within three days after exposure to infection. ${ }^{2} \mathrm{~A}$ recent report suggests that infected pregnant women should be admitted to an infectious diseases unit for treatment with intravenous acyclovir $(10 \mathrm{mg} / \mathrm{kg}$ every eight hours given slowly with 1 litre of fluid for each gram of acyclovir) to ameliorate the course of the disease. The fetus does not seem to be adversely affected. ${ }^{4}-$ J A B COLLIER

\section{Principal sources}

1 Paryani SG, Arvin AM. Intrauterine infection with varicella zoster virus after maternal varicella. $N$ Engl $\mathcal{H}$ Med 1986;314:1542-6.

2 Waterson AP. Virus infections (other than rubella) during pregnancy. BrMed f 1979;ii:564-6.

3 Evans EB, Pollock TM, Cradock-Watson JE, Ridehalgh MKS. Human antichickenpox immunoglobulin in the prevention of chickenpox. Lancet 1980;i:355-6.

4 Boyd $\mathrm{K}$, Walker $\mathrm{E}$. Use of acyclovir to treat chickenpox in pregnancy. BrMed f 1988;296:393-4. 